\title{
A ABORDAGEM DA TEMÁTICA INDÍGENA E DA HISTÓRIA DA ÁFRICA NOS LIVROS DIDÁTICOS: EXEMPLOS DE OFICINAS NA FORMAÇÃO DOCENTE
}

\author{
Ingrid Silva de Oliveira Leite ${ }^{1}$
}

Resumo: Os livros didáticos são o meio mais utilizado pelos professores de História, mesmo com o uso crescente da internet. As leis 10.639 e 11.645 tornaram obrigatório o ensino da História da África, da cultura afro-brasileira e da temática indígena, mas tais assuntos ainda não são tão explorados e problematizados nos livros didáticos, embora já se encontrem modificações importantes. Nos cursos de licenciatura em História, a África e os indígenas são estudados em um ou dois semestres, o que acreditamos ser pouco tempo para professores em formação. Uma saída seria a prática de oficinas utilizando os livros didáticos para refletir sobre a abordagem da História da África, da diversidade da experiência do negro no Brasil e da temática indígena. Este artigo objetiva refletir sobre as representações dessas temáticas em livros didáticos a partir de oficinas e a elaboração de aulas em cursos de licenciatura em História no Rio de Janeiro e Minas Gerais.

Palavras-chave: Oficinas. Ensino de História. África. Indígenas.

\section{THE APPROACH TO INDIGENOUS THEMES AND AFRICAN HISTORY IN TEXTBOOKS: AN EXPERIENCE IN TEACHER EDUCATION}

\begin{abstract}
Textbooks are the most used by history teachers, even with the increasing use of the internet. Laws 10,639 and 11,645 established the mandatory teaching of the history of Africa, Afro-Brazilian culture and indigenous themes, but such subjects are still not as demonstrated and problematized in textbooks, although important changes have already been found. In History degree courses, Africa and the natives of Brazil are studied in one or two semesters, which we believe is a short time for teachers in training. One way out would be the practice of workshops using textbooks to reflect on the approach to African history, the historical diversity of black people in Brazil and the indigenous theme. This article aims to demonstrate workshops with textbooks and preparation of classes in History degree courses in Rio de Janeiro and Minas Gerais.
\end{abstract}

Keywords: Workshops. History Teaching. Africa. Indigenous people.

\section{L'APPROCHE DES THÈMES INDIGÈNES ET DE L'HISTOIRE AFRICAINE DANS LES LIVRES DIDATIQUES : UNE EXPÉRIENCE DANS LA FORMATION DES ENSEIGNANTS}

Resumé: Les livres didatiques sont le plus utilisé par les professeurs d'histoire, même avec l'utilisation croissante d'Internet. Les lois 10639 et 11645 ont rendu obligatoire l'enseignement de l'histoire africaine, de la culture afro-brésilienne et des thèmes autochtones, mais ces sujets ne sont toujours pas comme démontré et problématisé dans les livres didatiques, bien que des

\footnotetext{
${ }^{1}$ Professora adjunta de História da África, Educação e Relações Étnico-raciais da Universidade Federal São João del Rei (UFSJ). É professora colaboradora do Programa de Pós-graduação em História da UFSJ e coordenadora da área de História do PIBID na mesma instituição. Possui experiência em temas referentes às sociedades africanas e à presença política, militar e religiosa de europeus no continente africano durante os séculos XVII e XVIII. Possui graduação e licenciatura em História pela UFRJ (2007), especialização em História da África e do Negro no Brasil pela UCAM e mestrado em história no Programa de Pós-graduação em História da UFRRJ (2011). Seus estudos de doutorado foram realizados no Programa de Pós-graduação em História da UFF (2015). Realizou atividades de pós-doutorado no Instituto Multidisciplinar da Universidade Federal Rural do Rio de Janeiro, na área de História da África.
}

Revista Escritas do Tempo - v. 2, n. 5, jul-out/2020 - p. 157-174 
changements importants aient déjà été trouvés. Dans les cours de licence d'histoire, l'Afrique et les natifs du Brésil sont étudiés en un ou deux semestres, ce qui nous semble être un court laps de temps pour les enseignants en formation. Une façon de sortir de cette limite serait la pratique d'ateliers utilisant des livres didatiques pour réfléchir sur l'approche de l'histoire africaine, la diversité de l'expérience des Noirs au Brésil et le thème indigène. Cet article vise à démontrer ateliers avec des manuels et la préparation de cours dans des cours de licence d'histoire à Rio de Janeiro et Minas Gerais.

Mots-Clés: Ateliers. Enseignement de l'histoire. Afrique. Indigène.

\section{EL ENFOQUE DE LOS TEMAS INDÍGENAS Y LA HISTORIA AFRICANA EN LOS LIBROS DIDÁCTICOS: UNA EXPERIENCIA EN LA FORMACIÓN DEL PROFESORADO}

Resumen: Los libros didácticos son el medio más utilizado por los profesores de historia, incluso con el uso cada vez mayor de Internet. Las leyes 10.639 y 11.645 hicieron obligatoria la enseñanza de la historia africana, la cultura afrobrasileña y los temas indígenas, pero tales temas aún no se demuestran y problematizan en los libros didácticos, aunque ya se han encontrado cambios importantes. En los cursos de licenciatura de Historia, África y los nativos de Brasil se estudian en uno o dos semestres, lo que creemos que es poco tiempo para los profesores en formación. Una forma de salir de este límite sería la práctica de talleres utilizando libros didácticos para reflexionar sobre el enfoque de la historia africana, la diversidad de la experiencia negra en Brasil y el tema indígena. Este artículo tiene como objetivo demostrar talleres con libros didácticos y preparación de clases en cursos de licenciatura en Historia en Río de Janeiro y Minas Gerais.

Palabras clave: Cursos. Enseñanza de la historia. África. Pueblos indígenas.

\section{A formação de professores e as leis 10.639 e 11.645}

A formação de professores é um momento no qual se pode experimentar diversas possibilidades. Estar em formação implica um investimento pessoal, livre e criativo sobre os percursos e projetos próprios, com vista à construção de uma identidade pessoal e profissional (NÓVOA, 1991). Logo, a formação docente não se resume a uma etapa da vida escolar, mas se processa ao longo da vida profissional dos sujeitos, se desenvolvendo no cotidiano, em tempos e espaços educativos diversos, uma vez que o saber docente é plural. O docente é um profissional que implica um domínio de saberes que são frutos de elaboração pessoal, decorrentes de um quadro de referências social e culturalmente construídos.

Vivemos em uma sociedade que requer o enfrentamento de práticas discriminatórias e preconceituosas. Por isso, o professor deve educar para a diversidade e respeito às diferenças. Os professores são insubstituíveis não só para as possibilidades de aprendizagens, mas também na elaboração de processos de inclusão que respondam aos desafios da diversidade e no desenvolvimento de metodologias adequadas para uso das novas tecnologias.

Revista Escritas do Tempo - v. 2, n. 5, jul-out/2020 - p. 157-174 
Ao analisar a formação nos cursos superiores de História, Selva Guimarães Fonseca (2003) afirma que os espaços de licenciatura devem possibilitar a articulação das atividades de ensino, pesquisa, extensão e das práticas pedagógicas. É na graduação que os saberes docentes são organizados como estruturantes da formação do professor e tal processo é dinâmico e ativo.

Formação e prática não são atividades distintas para os professores. Além disso, o inacabamento é a marca desse movimento. Por isso é muito importante que os cursos de licenciatura em História ofereçam mais momentos de reflexão sobre a prática docente e que os recursos disponíveis estejam relacionados às realidades discentes, de modo que os licenciandos se identifiquem e se interessem pela disciplina de História. Nesse sentido, cabe lembrar que apesar do uso crescente da internet, o livro didático ainda é a ferramenta mais utilizada pelo professor de História no Brasil.

Em 2003 foi criada a lei 10.639 e, no ano seguinte, o Conselho Nacional de Educação aprovou as Diretrizes Curriculares Nacionais para a Educação das Relações Étnico-Raciais e para o Ensino de História e Cultura Afro-Brasileira e Africana. Desse modo, foi definido o conteúdo programático a ser ensinado. Em 2008, a lei 11.645 alterou novamente a Lei de Diretrizes e Bases da Educação Brasileira e incluiu a obrigatoriedade da temática indígena ${ }^{2}$.

Segundo o historiador Anderson Oliva (2003), a África e suas múltiplas experiências históricas não foram apresentadas durante grande parte das trajetórias de vida e formações escolares de grande parte da população brasileira, a não ser por meio de informações que estavam recheadas de equívocos e simplificações. O autor atenta para o silêncio, o desconhecimento e as poucas experiências positivas referentes aos espaços africanos nas coleções de livros didáticos brasileiros. Apenas um número muito pequeno de manuais possui capítulos específicos sobre a temática. Por vezes, a África aparece apenas como um figurante que passa despercebido em cena, sendo mencionada como um apêndice misterioso e pouco interessante de outros assuntos (OLIVA, 2003, p. 429).

\footnotetext{
${ }^{2}$ Neste artigo, optou-se apenas por demonstrar autores que abordam questões para os livros didáticos de História. Contudo, há outros estudos importantes que analisam a representação dos negros nos livros didáticos de outras disciplinas. Para o caso de Língua Portuguesa, cf. SILVA, 2011. Para o caso da Geografia, cf. COSTA, R.L. S da; DUTRA, D. F. A lei 10639/2003 e o ensino de geografia: representação dos negros e África nos livros didáticos. In: $10^{\circ}$ Encontro nacional de Prática de Ensino em Geografia, 30 de agosto a 02 se setembro de 2009. Porto Alegre. Para o caso da Matemática, cf. OLIVEIRA, 2016.
} 
A professora e historiadora Mônica Lima aponta para a necessidade de criar referências nas escolas ao abordar pessoas negras que se destacaram, como João Candido, André Rebouças e outros. Além disso, ela enfatiza a importância de trabalhar conteúdos históricos fazendo relações com o espaço africano, como a questão de o processo de hominização de nossa espécie ter ocorrido na África, ou sublinhar a existência de civilizações poderosas na antiguidade como o Egito e Kush. Dessa maneira, a história estimularia nos alunos a criação de uma imagem positiva da África e dos africanos, trabalhando sua autoestima e fabricando uma maior identificação com esses grupos (LIMA, 2006, p. 73).

A autora ainda demonstra alguns temas que devem ser problematizados em sala de aula, como a ideia de que os indígenas não teriam se adaptado ao trabalho forçado e o escravo africano seria mais apto a este tipo de atividade ${ }^{3}$. Os jesuítas defendiam essa teoria apoiados por uma bula papal e um decreto real, que determinavam a captura apenas dos nativos que se rebelassem ou tivessem comportamento antirreligioso e protegia os recolhidos nas missões ${ }^{4}$. Os jesuítas possuíam milhares de escravos nos diversos colégios, seminários e residências, ou seja, pode-se inferir sobre o interesse jesuíta em referendar a escravidão africana.

Outro tema recorrente e que deve ser problematizado é a ideia disseminada de levar a "civilização" e a "salvação" para os africanos. Os povos do continente até hoje percebem reflexos desta atitude dita "civilizatória", desenvolvida pelos europeus, primeiramente, entre os séculos XVI e XIX, através do tráfico negreiro e, posteriormente, desorganizando as sociedades, devastando a natureza, apossando-se das riquezas e desestruturando as culturas (LIMA, 2006, p. 95).

A historiadora Mônica Lima salienta que é preciso abordar no ensino de História a diversidade das experiências históricas das pessoas que foram escravizadas. Deve-se destacar não apenas as fugas e revoltas, mas o modo como se organizavam em irmandades religiosas, os movimentos sociais e artísticos, em centros de cultura, lazer e educação, numa demonstração inequívoca de insatisfação com a sua condição de vida.

Certamente, o preconceito e a discriminação que envolvem a população negra no Brasil foram reforçados durante muito tempo no processo de ensino-aprendizagem de História. Isto se explicita na ausência da História da África nos currículos e livros

\footnotetext{
${ }^{3}$ Esse é um ponto fulcral para o debate. Afinal de contas, existiria algum grupo ou alguém que se "adapte" mais facilmente a algum tipo de trabalho forçado? O professor em sala de aula precisa levantar esse tipo de questão junto aos alunos.

${ }^{4}$ A chamada "guerra justa".
} 
didáticos durante tanto tempo e na valorização dada ao estudo da história geral, tendo por paradigma a história europeia. Por isso, é preciso sempre reavaliar a história ensinada e aprendida no Brasil, tirando do ostracismo aqueles que tiveram sua participação na construção desse país subvertida e/ou silenciada.

Marina de Mello e Souza também sugere abordagens sobre a história da África. A presença de exploradores europeus no continente africano é um tema interessante para ser trabalhado em sala de aula, por exemplo. É possível abordar questões metodológicas e de crítica documental relativas ao uso desses textos como fontes. $\mathrm{O}$ fator aventura pode captar a atenção de um adolescente ao demonstrar e problematizar os casos de Henry Stanley, Mungo Park, Richard Francis Burton, John Hanning Speke e James Augustus Grant ${ }^{5}$. Até mesmo uma produção bibliográfica anterior pode ser trabalhada, como a de exploradores e geógrafos europeus, eruditos árabes ou africanos islamizados 6 .

Além de abordar a história da África pelo viés das narrativas escritas, pode-se também estudar o continente utilizando as informações de natureza geográfica, as trocas culturais que permeavam as transações comerciais, a importância dos rios e a localização de grupos, por exemplo:

Ensinar História da África e aspectos da cultura afro-brasileira nas escolas parece ser um bom caminho para nos livrarmos de preconceitos historicamente constituídos e que ajudam a impedir que a população negra tenha igualdade de oportunidades diante da parcela mais branca, ou mais clara, dos brasileiros. Isso não tem nada a ver com estimular antagonismos entre as raças, num país composto de pessoas de ascendências variadas, ou seja, mestiças. Mas sim com valorizar o que há de africano, e consequentemente de negro, em todos nós, assim como devemos valorizar o que há de europeu, de oriental e de indígena. (SOUZA, 2008, p. 75)

Assim como a História da África, a temática indígena vem recebendo uma maior visibilidade no ensino de História. Desde 1990, os estudos históricos na academia deram novas dimensões para a agência das populações indígenas na história do Brasil, especialmente considerando o seu papel a partir da ocupação colonial portuguesa.

\footnotetext{
${ }^{5}$ Tais nomes se referem a europeus que produziram textos sobre regiões do continente africano entre os séculos XVIII e XIX.

${ }^{6}$ Importante também evidenciar o método de escrita utilizados por esses autores, que relatavam o que viram, ouviram e pesquisaram em documentos que tiveram acesso, como Al-Bakri, Al-Masudi, Ibn Matuta, Ibn Kaldun, As-Saadi e Yuhanna al-Asad. Isso também contribui para tornar possível uma série de materiais sobre uma África medieval, ao invés de uma compreensão do medievo permeada da presença da fé católica e do feudalismo europeu, que aparecem de forma predominante nos livros didáticos.
} 
Pensar o indígena nas relações sociais, culturais e econômicas em todo o contexto colonial concedeu-lhe novo papel na história (MONTEIRO, 1994).

Contudo, de acordo com vários autores que já se dedicaram a estudar as representações dos indígenas no livro didático, percebe-se que o ensino da temática não tem visibilidade. As análises de livros didáticos da primeira metade do século $\mathrm{XX}$ identificaram que as visões sobre tais povos estavam marcadas pelas noções da literatura romântica do século XIX, que mostram o indígena idealizado, representado a um só tempo como herói e vítima, fadado ao extermínio. Eles eram vistos como representantes do passado, só aparecendo como primeiros habitantes do Brasil (ZAMBONI; BERGAMASCHI, 2009, p. 56).

Os saberes selecionados oficialmente nas escolas desconsideram muitas vezes a pluralidade dos povos indígenas, hoje presentes na nação brasileira com centenas de etnias. Muitas vezes a imagem que construímos sobre os indígenas ocorre na infância e permanece por toda vida, pois são escassos os contatos com a temática ao longo da vida escolar. Essa visão deformada decorre da nossa história ser contada até hoje a partir da visão do colonizador, embora já se verifique uma pequena mudança em alguns casos.

Geralmente, quando os alunos do ensino básico são convidados a realizar desenhos sobre os indígenas, eles aparecem nus, pintados e em contato com a natureza. De acordo com essas representações, é evidente que a situação social contemporânea desses grupos não é abordada. (BERGAMASCHI; GOMES, 2012, p. 56). Considerando o conteúdo de História, a temática indígena ainda é tratada com muita ambiguidade e persiste uma visão que se aproxima da ideia de "homens ingênuos" e "vitimizados".

Em agosto de 2017, foram elaborados questionários para identificar as formas da aplicabilidade da temática indígena com os não índios nas escolas da rede pública estadual no município de Macapá, no Amapá, e como estas escolas estavam desenvolvendo seus conteúdos para abarcar a lei 11.645/2008. O estudo revelou que a maior parte dos professores reclamava da falta de materiais didáticos a respeito, além de se revelam mal informados sobre o assunto. A pesquisa também indicou que a temática indígena era abordada apenas em datas comemorativas (MIRANDA; PASTANA; FERRO, 2017, p. 10).

No ano de 2014, foi realizada análise de uma das coleções de livros de história mais utilizada no Brasil (distribuída pelo Programa Nacional do Livro Didático), que concluiu que os povos indígenas possuem três formas de visibilidade na coleção. A primeira delas é fugaz, composta de menções passageiras, nas quais não são 
aprofundadas as informações. A segunda delas é quando os grupos indígenas aparecem enquanto objeto da ação colonizadora (escravizados por uns, aldeados por outros). Não são enfatizadas as respostas dos indígenas para essas ações, sublinhando uma visão de que eram passivos, submissos e manipulados. Por fim, em poucos momentos da coleção busca-se construir conhecimentos sobre eles, dando destaque e aprofundamento nas informações. Mesmo possuindo referências bibliográficas atuais, a narrativa dos livros analisados é construída a partir de escolhas que negligenciaram informações que possibilitariam uma maior visibilidade aos povos indígenas, promovendo, portanto, um silenciamento sobre o papel desses povos na história do país (GANDRA; NOBRE, 2014, p. 55).

\section{Os livros didáticos}

De acordo com Selva Guimarães Fonseca, a maior parte dos especialistas estão de acordo que o livro didático é a ferramenta mais importante no ensino de História (FONSECA, 2003). O livro didático é o segundo gênero mais lido pelos brasileiros, ficando atrás apenas na Bíblia. Desde a criação do Fundo Nacional de Desenvolvimento da Educação (FNDE), o governo federal legisla sobre o livro didático, além de gerenciar sua circulação. Pensar o ensino de História e os materiais didáticos implica refletir sobre as relações entre o mercado (toda cadeia produtiva do livro), o Estado, a universidade, as escolas e os currículos e em ação nas aulas de História.

Pressupondo que os livros didáticos devem ser pensados como objetos culturais complexos, devemos compreendê-lo também como um documento histórico. Nesse sentido, deve-se atentar para a sua criação, produção editorial, comercialização, circulação, apropriação, utilização e leitura. Alain Choppin (2004, p. 554) defende que é muito complexo analisar esse tipo de material, pois eles assumem múltiplas funções das quais nós, enquanto pesquisadores, selecionamos as que mais se identificam com os nossos objetivos. Analisar criticamente os conteúdos dos livros didáticos e relacioná-los às discussões historiográficas e às demandas sociais, pensar seu suporte material, seus usos e desusos por professores e alunos, são algumas das maneiras possíveis de pesquisa.

O livro didático não merece ser visto como uma cópia mal cortada de conteúdos acadêmicos. Tampouco associar a utilização desse suporte a uma falta de competência dos professores. O livro didático como objeto pedagógico foi peça fundamental no lento e constante processo de construção curricular e formação de uma tradição escolar, para 
o conjunto de práticas e representações que marcaram o processo de escolarização moderna. $\mathrm{Na}$ escola existe uma tradição pedagógica que direciona o trabalho com os conteúdos que fazem parte da grade curricular por meio de uma série de dispositivos e normas que caracterizam a forma escolar de ensino para uma massa de estudantes.

De acordo com Erinaldo Cavalcanti (2018), o livro didático exerce grande influência no exercício da docência. O autor é um dos defensores da experiência com livros didáticos durante a formação docente, pois o livro não se resume ao texto (CAVALCANTI, 2018, p. 2). Além disso, o autor salienta que é o trabalho dos diagramadores, revisores e designers gráficos que oferece a primeira leitura para o público ao qual se destina, uma vez que a primeira interpretação da obra dependerá da leitura visual. A dinâmica da fabricação desse produto passou por significativas mudanças nos últimos anos, que sinalizam e representam projetos políticos em constantes disputas. Disputas que direcionam a composição dos livros na medida em que interferem na seleção dos conteúdos, da composição da narrativa, nas abordagens apresentadas, nas fontes utilizadas e na materialidade do próprio produto.

Um elemento importante a ser considerado na composição dos livros didáticos são as imagens que os compõem. Na intenção de tornar o conteúdo histórico mais atrativo, as ilustrações são usadas em grande quantidade. As imagens, como fragmentos do todo, não podem ser percebidas desarticuladas do universo social em que estiveram inseridas quando produzidas (COSTA, 2005). Warley Costa defende a necessidade de observação e problematização do que elas nos dizem a respeito das culturas em que foram produzidas e suas finalidades ao serem criadas: "Elas foram produzidas para ilustrar determinado texto, para ornamentar determinada peça de arte ou para registrar o presente vivido para a posteridade? São realistas?” (COSTA, 2005, p. 148).

Sem o devido questionamento por parte dos professores em sala de aula, problemas graves podem ocorrer. Costa afirma que nos livros didáticos de História que analisou observou grande quantidade de imagens que informavam sobre as condições de vida dos cativos, reforçando a trajetória de vida sofrida, de permanente dor. Para a autora, o manual didático se configura como instrumento de divulgação de uma memória que com suas gravuras e fotografias passam a constituir importantes acervos selecionados de acordo com sua significação para diferentes grupos. Com a intenção de observar as imagens que existiam sobre o tema escravidão, Costa revela que as denúncias necessárias demonstradas pelas imagens são importantes, mas relegam ao escravo o papel de agente absolutamente passivo: "Sem movimento próprio, sem 
nenhuma possibilidade de autonomia, ele se transformaria num ser desprovido de qualquer ação humana" (COSTA, 2005, p. 154). Desse modo, ignorar aspectos da cultura, das relações sociais e afetivas que se estabeleciam na sua vivência cotidiana é silenciar. É preciso considerar que, mesmo sob o cativeiro, as pessoas criaram relações sociais específicas, que precisam ser demonstradas para os alunos nas aulas de história.

Como enfatiza Maria Auxiliadora Schmidt (2011, p. 133) é bastante sintomático que ainda não tenhamos uma disciplina nos cursos de formação docente que se encarregue especificamente de trabalhar o livro didático em suas múltiplas dimensões. Sabemos que o processo de apropriação e as possibilidades de usos dos livros didáticos dependem de muitas variantes. As práticas de apropriação são múltiplas e dependem da relação de forças em que são construídas. A formação de professores é o espaço por excelência onde podemos e devemos experimentar possibilidades e, por extensão, interpretar as práticas e representações docentes acerca do livro didático de história em sala de aula.

O livro didático é uma fonte útil para a cultura escolar. Todavia, ele não deve ser o único material a ser explorado. Submetido à uma leitura crítica, com a ajuda interpretativa do professor e colocado em diálogo com outras fontes de estudo, ele pode contribuir de modo significativo para a aprendizagem da História. Ao mesmo tempo, nem tudo está no livro didático: o ensino se dá por múltiplos caminhos, logo a produção de materiais didáticos, vinculada a realidades específicas de aprendizagem, deve ser apoiada e valorizada (FONSECA, 2003).

Ainda segundo Selva Guimarães Fonseca, é necessária uma revisão dos modos de uso dos livros didáticos. A autora defende a complementação dessa ferramenta, como a diversificação das fontes históricas e o uso de paradidáticos, mídias e linguagens. A sala de aula não é um mero espaço de reprodução de conteúdo, logo, requer dos professores uma postura de criticidade diante do que é veiculado. Especialmente porque a perspectiva curricular da disciplina História ainda é baseada num critério temporal, linear eurocêntrico, articulada, quando possível, à História do Brasil, da América e da África. Para a autora, isso se evidencia ainda mais com o uso de apostilas, que simplificam, fragmentam e reduzem a versões simplificadas e acríticas o conhecimento histórico. Os livros didáticos são, portanto, representativos para a compreensão da difusão do saber histórico (FONSECA, 2003). 


\section{Oficinas com livros didáticos na formação de professores de história}

Gostaríamos de demonstrar algumas oficinas realizadas em cursos de licenciatura em História em duas universidades federais do Sudeste brasileiro. Trata-se de oficinas de análise de livros didáticos e de elaboração de aulas temáticas referentes à África e à temática indígena. É preciso salientar que as coleções de livros didáticos não apresentam as mesmas abordagens sobre os temas que nos interessam neste artigo. Portanto, as visões demonstradas aqui se referem às impressões dos alunos de licenciatura sobre os livros didáticos utilizados nas oficinas que realizamos ${ }^{7}$.

Parte das oficinas ocorreu em 2018 na Universidade Federal Rural do Rio de Janeiro (UFRRJ) na disciplina optativa "Ensino de história da África e indígena na educação básica". O objetivo da disciplina era refletir sobre o ensino de história da África, africanos e história indígena e seus impactos na educação básica e superior, além de inferir sobre seus reflexos na produção de material didático e na formação de professores de história. Já no ano de 2019, as oficinas foram realizadas na disciplina “Educação e Relações Étnico-raciais", também optativa, na Universidade Federal de São João del-Rei (UFSJ). Nesta disciplina, separamos um módulo para analisar as desigualdades étnico-raciais na sociedade brasileira, relacionando-as aos estudos sobre diversidade na área educacional. Num segundo módulo, o objetivo era refletir sobre África, indígenas e negros no Brasil, representados nos livros didáticos, e pensar estratégias de abordagens para os temas, considerando os principais mitos e dificuldades. Finalmente, num terceiro módulo o objetivo era demonstrar e estimular estratégias de superação do racismo na educação e, em especial, discutir as políticas de ação afirmativa e as leis 10.639/2003 e 11.645/2008.

Em ambas as situações, as oficinas foram realizadas em grupos de três a quatro pessoas. Cada grupo recebia aleatoriamente um livro didático de História do Ensino Fundamental II (do $6^{\circ}$ ao $9^{\circ}$ ano) e deveria analisá-lo por cerca de 60 minutos, respondendo a algumas questões específicas. Em seguida, formávamos uma roda de conversa e os grupos apresentavam suas impressões. É importante pontuar que, antes dessa oficina, foram apresentados e debatidos textos que falavam sobre as

\footnotetext{
${ }^{7}$ Foram analisados os seguintes livros didáticos: APOLINÁRIO, 2010. 4 v. (do $6^{\circ}$ ano $9^{\circ}$ ano); BOULOS JÚNIOR, 2012. 4 v. (do $6^{\circ}$ ano $9^{\circ}$ ano); BRAICK, 2001. 4 v. (do $6^{\circ}$ ano $9^{\circ}$ ano); VAZ; PANAZZO, 2012. 4 v. (do $6^{\circ}$ ano $9^{\circ}$ ano).
} 
singularidades dos livros didáticos e as representações da África, dos africanos e indígenas nessas obras ${ }^{8}$.

Os alunos de licenciatura demonstraram bastante entusiasmo em trabalhar com os livros didáticos. Alguns comentavam que havia muito tempo que não tinham contato com um livro daquele tipo ou que "estavam curiosos" de saber como eram os livros didáticos de "hoje em dia". Também ficou evidente o desejo dos alunos de analisarem e trabalharem os livros didáticos em outras situações e em outras disciplinas. Os alunos expressaram seu desejo de um maior enfoque à preparação para a prática docente pelas instituições, embora reconhecessem a importância da preparação para a pesquisa histórica.

Após opinarem sobre a proposta da atividade, partíamos para o compartilhamento de suas impressões sobre os livros. Na primeira oficina, as perguntas que orientavam as análises foram: qual o ano de publicação do livro? Quais são os autores e suas formações? Qual o público-alvo do livro? Quais imagens representavam a África ou os africanos? Ou os negros no Brasil? Que tipo de reação elas causavam? Existe algum texto em referência à imagem? Do que se trata? Na sua visão, como o aluno entenderia o papel do negro ou africano em questão? De uma maneira positiva ou negativa? Explique.

Em uma outra aula, ocorria outra oficina, com perguntas diferentes, focando na temática indígena. As perguntas eram: quais capítulos/unidades existem no livro que abordam a questão indígena no Brasil? Como os indígenas são caracterizados? Seus comportamentos? Existem imagens? Existe uma contextualização para tais imagens ou são usadas apenas como ilustração? Você utilizaria esse livro para abordar a questão indígena ou se sentiria mais seguro produzindo um material próprio?

Percebeu-se que, tanto para a análise da África, africanos e seus descendentes no Brasil quanto para o caso indígena, houve uma atenção especial às imagens que existiam nos livros. Esse recorte foi realizado tendo em vista o tempo para a análise (60 minutos cada oficina) e levando em consideração o impacto que elas podem causar no público-alvo, visto que os alunos do Ensino Fundamental II são mais afetados por elas do que por grandes textos informativos.

Em ambas as situações, os alunos expressaram que os livros didáticos sempre apresentariam algum tipo de "problema", especialmente se comparados às pesquisas

\footnotetext{
${ }^{8}$ Especialmente os textos de Anderson Oliva, Warley Costa, Monica Lima, Gandra e Nobre e Grupioni. As referências completas dos textos seguem nas referências bibliográficas.
} 
acadêmicas. Foi interessante notar essa percepção que possuíam sobre o livro didático não ser uma "vulgarização" do saber acadêmico, mas um saber diferente e que precisa de uma mediação importante do professor.

Com relação às imagens, os alunos da licenciatura destacaram algumas imagens que faziam referências à Copa do Mundo de 2010, realizada na África do Sul, e a figuras como Nelson Mandela. A maior parte das imagens referiam-se a uma história contemporânea do continente, no caso dos livros do $9^{\circ}$ ano. Com relação ao $6^{\circ}$ ano, chamaram a atenção as imagens do Egito e do destaque dado a sua localização no continente africano, bem como a referência à origem africana da espécie humana. Nesses casos, as imagens foram entendidas de maneira bastante positiva. $\mathrm{O}$ caso do $7^{\circ}$ ano foi o que mais espantou os alunos, ao perceberem as páginas que falavam sobre Reinos de Gana, Mali, Songhai e a influência dos povos Banto e Iorubá no Brasil. Muitos diziam não ter visto tal conteúdo em sala de aula e que também teriam dificuldade de abordar o tema quando se tornassem professores de História por conta da falta de contato com tais temas.

O caso mais grave apontado pelos alunos ocorria nos livros didáticos do $8^{\circ}$ ano. Eram raras as imagens do continente, exceto por mapas que faziam referência ao tráfico de pessoas escravizadas. Ou seja, nesse momento, os alunos tiveram a impressão de que a única leitura que teriam da África seria como "mera fonte de escravos". Além disso, contestaram o fato de existirem poucas informações sobre a experiência histórica dos africanos e de seus descendentes no Brasil, dando a entender que todos eles vieram como escravos e permaneceram como tal até a chegada dos imigrantes europeus e a chamada "política de embranquecimento", promovida pelo governo brasileiro. Os alunos da licenciatura disseram que os negros pareciam "sumir" no livro didático quando a imigração europeia começou e só reapareceram na Revolta da Chibata (já no livro de $9^{\circ}$ ano). Mesmo assim, não existia um contexto do papel do negro na sociedade do pós-abolição.

Para o caso indígena, os alunos da licenciatura perceberam certa presença de imagens sobre os povos nativos nos livros do $6^{\circ}$ ano. Nos livros didáticos do $7^{\circ}$ ano, as imagens demonstravam os indígenas apenas como "pano de fundo" da chegada dos portugueses na América. Nos livros de $8^{\circ}$ e $9^{\circ}$ ano, eles não apareciam. Apenas em um livro do $9^{\circ}$ ano aparecia a figura de um indígena e um texto referente aos direitos adquiridos pelo grupo no contexto da criação da Constituição Brasileira de 1988. Ou seja, foi unânime a impressão de que, nos livros didáticos, os indígenas quase não 
aparecem ou, quando aparecem, são abordados de forma superficial, "presa" ao passado e sem aprofundamento sobre questões atuais vivenciadas por esses povos.

Após as trocas de informações e debates levantados pelas oficinas, foram apresentados temas referentes à África, aos africanos e seus descendentes no Brasil e aos indígenas, que poderiam ser trabalhadas no Ensino Fundamental II e Médio. Cada aluno sorteou um tema e, ao longo do semestre, deveria elaborar uma aula tendo a própria turma como ouvinte. Cientes das características e limitações dos livros didáticos, os alunos foram estimulados a pensar suas abordagens de maneira problematizada, colaborando para a construção de um saber escolar que fosse além das informações dos livros didáticos.

\section{Aulas elaboradas para além do livro didático: dois casos}

Os alunos de licenciatura em História tiveram orientações em seus planos de aula e foram incentivados a consultar outras fontes de conhecimento. O livro didático deveria funcionar apenas como um apoio. O resultado desse processo foi muito satisfatório. Foram aulas bem dinâmicas e interessantes. Alguns usaram fontes históricas escritas e materiais, filmes, trechos de obras literárias, games e outros materiais. Surpreendeu positivamente a valorização que os alunos de licenciatura deram para a questão da oralidade, marcando a sua importância para as sociedades africanas, as religiões afro-brasileiras e também para pensar os indígenas. Além disso, foram apresentadas referências de produções musicais contemporâneas indígenas e africanas. Os alunos demonstraram bastante entusiasmo em ministrar as aulas e contar com o feedback da própria turma em seguida.

Dentre as aulas, gostaríamos de destacar dois casos: um que ocorreu no Rio de Janeiro e outro em Minas Gerais. A primeira abordando a história do continente africano e a segunda, a temática indígena.

Caso 1

$\mathrm{Na}$ Universidade Federal Rural do Rio de Janeiro, um aluno do $7^{\circ}$ período da licenciatura de História teve que escolher um tema de "África contemporânea”, que deveria ser pensado para um público de $9^{\circ}$ ano do Ensino Fundamental II. O licenciando iniciou sua aula ressaltando a complexidade desse período e que, como cada país africano teve sua singularidade, ele destacaria apenas um caso como exemplo: o da guerra civil de Ruanda, em 1994. Depois, ele distribuiu um questionário com perguntas 
rápidas para serem respondidas por cada um que assistia sua aula, alegando que queria conhecer a todos melhor. A surpresa foi grande quando recebemos o questionário e percebemos perguntas como: "qual é o seu time?"; "você come carne?"; "você se sente melhor andando calçado ou descalço em sua casa?”. Especialmente, nos perguntávamos “o que isso tem a ver com a matéria?". Depois de 5 minutos, devolvemos os questionários respondidos e ele rapidamente os analisou. $\mathrm{O}$ aluno então declarou que aqueles que "torciam para o flamengo", "não comiam carne" e "andavam calçados em casa" teriam privilégios durante a aula, pois pensavam como ele. Esse grupo foi separado dos demais, que começaram a "reclamar", pois não teriam as mesmas condições. Finalmente, o autor da aula nos revelou que os sentimentos de descontentamento e rivalidades vividos minimamente ali naquela experiência foram vivenciados por grupos maiores e de forma muito grave. Então, explicou como as rivalidades entre Hutus e Tutsis foram agravadas pela Bélgica a partir de $1910 \mathrm{em}$ Ruanda, pelas classificações feitas sobre a população local ${ }^{9}$. Em seguida, explicou como tais rivalidades levaram ao genocídio ocorrido e passou algumas cenas editadas do filme Hotel Ruanda. A aula foi finalizada apresentando as seguintes perguntas: "como você se sentiria se fosse um Hutu naquele contexto?"; “como você se sentiria se fosse um Tutsi naquele contexto?".

Caso 2

Em 2019, na Universidade Federal de São João del-Rei, uma aluna no $6^{\circ}$ período tinha como tema o "Encontro das culturas indígenas e portuguesa" no contexto da chegada lusitana na América. O público-alvo eram alunos do $7^{\circ}$ ano. A aluna da licenciatura distribuiu fragmentos do texto "O ritual do corpo entre os Sonacirema", de autoria de Horace Minner. O artigo é uma crítica ao modo de vida americano, especialmente no que se refere ao "ritual do corpo". É uma crítica para a facilidade de como aceitamos nossas práticas como naturais e repudiamos os costumes de outras comunidades entendidas como crenças "sem fundamento". A crítica de Minner revela que a nossa sociedade conserva o mesmo estilo ritualístico existente em outras comunidades. Segue um trecho do texto, para uma melhor compreensão:

\footnotetext{
${ }^{9}$ Obviamente as situações e sentimentos vivenciados naquele contexto não podem ser minimizados e tratados de forma pejorativa. Essa não foi a intenção da atividade proposta. O aluno esclareceu que, por se tratar de uma aula planejada para o $9^{\circ}$ ano do Ensino Fundamental II, a experiência possibilitaria que aqueles que estivessem na aula se imaginassem no lugar das pessoas durante a explicação das condições de diferenciação provocadas, levando a um movimento de empatia e um exercício de imaginação histórica, ou seja, uma forma de construir o conhecimento de forma mais ativa.
} 
Os Sonaciremas nutrem um misto de horror e fascinação por suas bocas que chega às raias da patologia. Acredita-se que a condição da boca possui uma influência sobrenatural nas relações sociais. Assim, o ritual do corpo, cotidianamente realizado por todos, inclui um rito bucal. $\mathrm{O}$ rito consiste na introdução de um pequeno feixe de cerdas na boca, juntamente com uma espécie de creme mágico e, em seguida, na movimentação deste feixe, segundo uma série de gestos altamente ritualizados. (MINNER, 1976, p. 3)

A crítica contida no texto não foi explicada para a turma inicialmente. A aluna apenas distribuiu os fragmentos do texto e, em seguida, pediu para que cada aluno da licenciatura lesse em voz alta o seu fragmento. Ao mesmo tempo, ela escrevia no quadro as ideias principais de cada trecho. Ao final da leitura de todos, ela perguntou se a turma tinha ideia de qual sociedade o texto abordava. Como recebeu uma resposta negativa de todos, ela revelou que se tratava dos "americanos", que é a palavra sonacirema ao contrário. Todos ficaram surpresos com a revelação daqueles hábitos serem comuns ao nosso cotidiano, momento em que ela solicitou que todos, novamente, lessem os trechos, mas agora com outra visão. Finalmente, ela refletiu sobre o conhecimento que possuímos dos povos indígenas e, em que medida, os conhecemos ainda pela lente do outro e não deles próprios, uma vez que as fontes escritas do período foram criadas pelos europeus, e não pelos nativos. A aluna finalizou a aula abordando a necessidade de valorizarmos a alteridade e criar um senso crítico sobre o que sabemos sobre os indígenas.

\section{Considerações finais}

A obrigatoriedade dos temas estabelecidos pelas leis 10.639 e 11.645 foram frutos de muita luta política. Mais do que isso, uma luta para dar um novo lugar para a história de grupos fundamentais para a nossa história, mas que foram subalternizados e silenciados ao longo do tempo. Contudo, pouco adianta fazer reformas curriculares se estas não forem ligadas à formação de professores. O currículo é construído, produzido nas relações de poder e saber, nas práticas, nas escolhas, nas culturas escolares e acadêmicas. É preciso criar cada vez mais experiências para refletir sobre a prática docente, especialmente pensando a abordagem dos temas colocados pelas leis de $2003 \mathrm{e}$ 2008. Desse modo, é possível contribuir para a formação de professores que valorizem o saber escolar e que tenham capacidade de reconhecer os limites dos livros didáticos e se motivem a ir além, produzindo materiais próprios ou buscando outras fontes de 
conhecimento e formas de abordagem, conforme os dois casos demonstrados neste artigo.

É fundamental refletir sobre o papel do livro didático na formação dos professores de História, para que os alunos de licenciatura entendam os diversos usos que podem ser atribuídos a ele. Não se trata de diminuir seu valor como ferramenta didática, mas de reconhecer a importância de outras abordagens do conteúdo de história, identificá-las e refletir sobre seus usos.

As atividades demonstradas neste artigo têm como objetivo promover ideias e estimular mais exercícios do gênero. Nos dias de hoje, os alunos do ensino básico possuem muitas informações, que são disponibilizadas por diversos meios. O professor de História é aquele que demonstra a importância do senso crítico e o respeito às diferenças. É preciso que os alunos de licenciatura se sintam motivados a pensar o ensino de História como um meio de promover uma sociedade melhor. A temática indígena, a história da África e a diversidade da experiência histórica dos negros no Brasil trabalhadas de maneira responsável no cotidiano da sala de aula são oportunidades de compreender e refletir sobre as origens do racismo - e suas estruturas - no país, a persistência da visão folclórica e o preconceito para com determinados grupos sociais. E, mais do que pensar nas origens, refletir sobre maneiras de combatêlas.

\section{Referências}

APOLINÁRIO, Maria Raquel (Ed.). Projeto Araribá: História. 3. ed. São Paulo: Moderna, 2010. 4 v.

BERGAMASCHI, M. Aparecida; GOMES, Luana. A temática indígena na escola: ensaios de educação intercultural. Currículo sem Fronteira, v. 12, n. 1, p. 53-69, jan. /abr. 2012.

BITTENCOURT, Circe M. F. Ensino de História: fundamentos e métodos. São Paulo: Cortez, 2005.

Livros didáticos entre textos e imagens. In: BITTENCOURT, Circe (Org.). $O$ saber histórico na sala de aula. São Paulo: Contexto, 1998. p. 69-90.

BOULOS JÚNIOR, Alfredo. História sociedade \& cidadania. 2. ed. São Paulo: FTD, 2012. $4 \mathrm{v}$.

BRAICK, Patrícia Ramos. Estudar História: das origens do homem à era digital. São Paulo: Moderna, 2001. 4 v. 
CAVALCANTI, Erinaldo. História, ensino de história e livro didático: a formação docente em debate. Saculum-revista de história, João Pessoa, n. 38, p. 1-12, jan./jun. 2018.

CHOPPIN, Alain. História dos livros e das edições didáticas: sobre o estado da arte. Educação e Pesquisa, São Paulo, v. 30, n. 3, p. 549-566, set./dez. 2004.

COSTA, Warley. Olhares sobre as Imagens da Escravidão Africana Dos pintores viajantes aos livros didáticos de história do ensino fundamental. Acervo, Rio de Janeiro, v. 18, n. 1-2, p. 147-160, jan. /dez. 2005.

FONSECA, Selva Guimarães. Didática e prática de ensino de História: experiências, reflexões e aprendizados. Campinas, SP: Papirus, 2003.

GANDRA, Edgar Ávila; NOBRE, Felipe Nunes. A temática indígena no ensino de História do Brasil: uma análise da coleção didática Projeto Araribá (2008-2013). Revista do Lhiste - Laboratório de Ensino de História e Educação, v. 1, n. 1, p. 40-57, jul./dez. 2014.

GRUPIONI, Luís Donizete. Livros didáticos e fontes de informações sobre as sociedades indígenas. In: SILVA, Aracy Lopes; GRUPIONI, Luís Donizete (Org.). A temática indígena na escola: novos subsídios para professores de $1^{\circ}$ e $2^{\circ}$ graus. Brasília: MEC; MARI; UNESCO, 1995. p. 481-526.

LIMA, Mônica. Fazendo soar os tambores: o ensino de História da África e dos Africanos no Brasil. Cadernos PENESB, v. 1, p. 159-173, 2000.

História da África: temas e questões para a sala de aula. Cadernos PENESB, Rio de Janeiro, Niterói, n. 7, p. 68-101, 2006.

MINNER, Horace. Ritos corporais entre os Sonacirema. In: ROONEY, A.K.; VORE, P.L. You and the others: readings in introductory Anthropology. Cambridge: Erlich, 1976. Disponível em:

$<$ https://edisciplinas.usp.br/pluginfile.php/364413/mod_resource/content/0/Nacirema.pd f>. Acesso em: 15 fev. 2020.

MIRANDA, Ana Paula Teixeira; PASTANA, Jéssica Joyce Rodrigues; FERRO, Simão Junior. A aplicabilidade da lei $11.645 / 08$ dentro das práticas pedagógicas. In: ENCONTRO DE DISCENTES DE HISTÓRIA DA UNIFAP. 3., 2017, Macapá. Anais... Macapá: [s. $\quad 1.], \quad 2017$ Disponível em: $<$ https://www2.unifap.br/cepap/files/2017/10/ANA-PAULA-JESSICA-ESIM\%c3\%83O-A-APLICABILIDADE-DA-LEI-11.645-08-DENTRO-DASPR\%c3\%81TICAS-PEDAG\%c3\%93GICAS.pdf>. Acesso em: 12 jan. 2019.

MONTEIRO, John Manuel. Negros da terra: índios e bandeirantes nas origens de São Paulo. São Paulo: Companhia das Letras, 1994.

NÓVOA, A. Formação contínua de professores: realidades e perspectivas. Aveiro: Universidade de Aveiro, 1991. 
OLIVA, Anderson Ribeiro. A História da África nos bancos escolares. Representações e imprecisões na literatura didática. Estudos Afro-Asiáticos, ano 25, n. 3, p. 421-461, 2003.

Entre máscaras e espelhos: reflexões sobre a Identidade e o ensino de História da África nas escolas brasileiras. Revista História Hoje, v. 1, p. 29-44, 2012.

SCHMIDT, Maria Auxiliadora Moreira dos Santos. Manuais de didática da história destinados à formação de professores e a constituição do código disciplinar da história no Brasil: 1935-1952. História, v. 30, n. 2, p.126-143, 2011.

SOUZA, Marina de Mello e. Um continente no currículo. Revista de História, Rio de Janeiro, p. 72-75, nov. 2008.

VAZ, Maria Luísa; PANAZZO, Silvia. Jornadas.hist: História. São Paulo: Saraiva, 2012. $4 \mathrm{v}$.

ZAMBONI, Ernesta; BERGAMASCHI, Maria Aparecida. Povos indígenas e ensino de história: memória, movimento e educação. In: CONGRESSO DE LEITURA DO BRASIL, 17., 2009, Campinas. Anais... Campinas: Associação de Leitura do Brasil, 2009. Disponível em: < http://alb.com.br/arquivomorto/edicoes_anteriores/anais17/txtcompletos/sem12/COLE_3908.pdf >. Acesso em: 15 ago. 2019. 